\title{
Impact of developed information package on UV protection for knowledge gain among women consumer
}

Received: 13.08.2016; Revised: 12.10.2016; Accepted: 27.10.2016

See end of the paper for authors' affiliations

\section{MEENU SRIVASTAVA}

Department of Textiles and Apparel Designing, College of Home Science, Mharanapratap University of Agriculture and Technology, UDAIPUR (RAJASTHAN) INDIA
ABSTRACT : The present study examines the impact of developed information package of UV protection through appropriate textiles among women consumers of Udaipur city of Rajasthan. This study is a follow up study based on the findings of previous study on consumer survey to assess knowledge about UV radiation and its harmful effects on human conducted by the researcher herself on 180 sample subjects comprised of working women and college going girls of Udaipur city which emphasized the need to develop information package on UV protection through textiles and generate awareness programme for women consumers. Total 30 women consumers were selected for imparting knowledge and generating awareness through developed information package on UV protection. Pre and post-test research design was used for present study. Findings revealed that the respondents were having very low knowledge about all the aspects of UV protection. Significant improvement in the knowledge was found as a result of awareness generation programme through developed information package as the pre-test score increased from 31.33 to 68.66 per cent with gain in knowledge of about 37.33 per cent.

KEY WORDS: Impact, Information, Package, UV radiation, Women, Knowledge, Gain

- HOW TO CITE THIS PAPER : Srivastava, Meenu and Tripathi, Smriti (2016). Impact of developed information package on UV protection for knowledge gain among women consumer. Asian J. Home Sci., 11 (2) : 373-377, DOI: 10.15740/HAS/AJHS/11.2/373-377. 